\title{
Long Term Change Point Detections in Total Ozone Column over East Africa via Maximal Overlap Discrete Wavelet Transform
}

\author{
J. W. Makokha ${ }^{* 1,3}$, H. K. Angeyo ${ }^{1}$, N.J. Muthama ${ }^{2}$
}

${ }^{1}$ Department of Physics, University of Nairobi, Nairobi, Kenya

${ }^{2}$ Department of Meteorology, University of Nairobi, Nairobi, Kenya

${ }^{3}$ Department of Science, Technology and Engineering, Kibabii University, Bungoma, Kenya

ABSTRACT: Change point analysis (CPA) for the detection of both natural or artificial discontinuities and regime shifts in Total Ozone Column (TOC) aids in inferring its influence on regional climate change. Assessment of temporal variability in climate is complex and requires the utilization climate models that are known to exhibit autocorrelation which enhances their capabilities in detecting either gradual or abrupt changes in TOC. Normally, changes in TOC may be associated to instrumentation changes or anthropogenic influence. This study presents for the first time, the utilization of Maximal Overlap Discrete Wavelet Transform (MODWT) in performing long term change point detections in TOC over East African from 1978 to 2013. This is because MODWT is not affected by circular shifting of the input series and also, its multiresolution capabilities allows for long term change point detections in TOC. Additionally, MODWT automatically separates the trend from the time series data therefore estimating the autocorrelated trend data. Results show that utilization of MODWT reveals no interannual change points detected in the TOC measurements over the region, therefore implying that TOC properties remained relatively constant interannually during the study period. On the seasonal scale, TOC variability was evident and may be connected to biomass burning as well as the temporal evolution in precursor emissions such as carbon dioxide $\left(\mathrm{CO}_{2}\right)$, Methane $\left(\mathrm{CH}_{4}\right)$ and Nitrogen oxides $\left(\mathrm{NO}_{X}\right)$. Photochemical oxidation during the December-January-February (DJF) season characterized by elevated temperatures explains the enhanced variability in TOC. However, dry spells with minimal temperature experienced (during June-July-August (JJA)) may explain the single or no observed change points during the study period. During wet season i.e. March-April-May (MAM) and September-October-November (SON) the TOC variability may be associated with biomass and refuse burning, lightening and extreme rainfall and intrusion of stratospheric air over the region.

Keywords: East Africa; Total Ozone Column, Maximal Overlap Discrete Wavelet Transform; Change Point Detections, Trend analysis.

\section{INTRODUCTION}

It is widely recognized that long-term changes in global temperature or other climatic variables exhibit abrupt shifts and nonlinearities in their behavior (Beaulieu et al., 2012). These abrupt shifts include regime shifts such as the pacific decadal oscillations that have serious implications particularly on the ocean ecosystem. On the other hand, strong ultraviolet absorption and greenhouse effect of Ozone $\left(O_{3}\right)$ plays a major role in modulating atmospheric radiation balance (Forster and Shine, 1997). Diminishing global total Ozone column (TOC) has been attributable to anthropogenic influence (Zhang et al., 2014). Statistical investigations on change point detection in monthly TOC series analysis paves ways for scientists to determine whether climate change has taken place or not. Change point analysis (CPA) is the process of detecting distributional changes within time-ordered observations (James and Matteson, 2013). 
The concept of change point analysis derives its applications from bioinformatics (Muggeo and Adelfio, 2011), detect credit fraud (Bolton and Hand, 2002), climate science (Sneyers, 1997) among other applications. CPA can be applied in various fields among them Multivariate data sets such as TOC measurements from remotely sensed spectroscopic techniques for classification in data mining (Mampaey and Vreeken, 2011). The multivariate nature of satellite retrieved TOC requires a CPA technique that effectively and quantitatively identify and map the change points in a given atmospheric property i.e. TOC. There exist a number techniques which can be applied in various scenarios to determine change detection in any given time series data.

These are: variance detection using Maximal Overlap Discrete Wavelet Transform (MODWT) and those in R-Statistics software through R packages that are known to perform Bayesian single CPA of univariate and multivariate time series; these are change point, ecp, cpm and bcp packages (Erdman and Emerson, 2007). Distributional changes can be identified by making use of the energy statistic of Székely and Rizzo $(2005,2010)$. The ecp package can freely be obtained at http://cran.r-project.org/web/packages/ecp/.

Change detections within linear regression models have been implemented in the strucchange package (Zeileis et al., 2002). Most of the tools embedded in the strucchange package focus on detecting at most one change within the regression model but at the same time performing online change detection which allows for multiple change point detection. Moreover, if the number of changes is known a priori then the breakpoints method can be used to perform retrospective analysis (Zeileis et al., 2002). For a given number of changes, this method returns the change point estimates which minimize the residual sum of squares (James and Matteson, 2013).

Studies pertaining the variability in TOC over the region have been documented (Edward et al., 2003; Diab et al., 2004; Bortz and Prather, 2006; Denman et al., 2007; Ongoma et al., 2013; Shilenje and Ongoma, 2014; Thompson et al., 2014; Mutai et al., 2015; Songa et al., 2015). From these studies, it was established that variability in both tropospheric ozone and TOC is dependent on available solar radiation, temperature fluctuations, winds, seasons, anthropogenic influence and altitude among other factors.

Ground and satellite based Ozone measurements have been underway over the East Africa. This has facilitated ground truthing of Ozone data derived from satellite overpass and ground based Dobson spectrophotometer and Ozonesonde data over the region. From studies by Lähnemann (2004), the Differential Optical Absorption Spectroscopy (DOAS), measurements were ground truthed with that from TOMS, Scanning Imaging Absorption Spectrometer for Atmospheric Chartography (SCIAMACHY) and the Global Ozone monitoring experiment (GOME), as well as the Ozonesondes of Nairobi and found a very good agreement in trend for all instruments. The root-mean-square values of the deviations from DOAS were less than $3.5 \%$ and the mean deviations were below (<1.5\%) (Lähnemann, 2004). Correlation between the different data sets from ground and satellite based measurements projected a deviation $<5 \%$.

In the current study, we propose an algorithm based on MODWT to perform long term change point detections in TOC over East Africa from 1978 to 2013. Multiresolution capabilities of MODWT and the fact that it is not affected by circular shifting of the input series (Percival and Walden, 2000) together with the time-ordered property of most spectroscopic measurements allowed for the development of an algorithm to detect longterm change point detection in TOC. TOC enhance studies on Ozone enhancement associated with dynamic and chemical processes such as biomass burning and El Nino events (Valks et al., 2014).

\section{METHODOLOGY}

\section{Maximal Overlap Discrete Wavelet Transform (MODWT)}

The MODWT is linear filtering operation that transforms a series into coefficients related to variations over a set of scales (Safari, 2008). The MODWT consists of basis vectors associated with a location $t$ and unit less scale 
$\delta_{j}=2^{j-1}$ for each decomposition level $J=1, \ldots \ldots . J_{0}$. It is of significance to note that MODWT retains down sampled values at each level of decomposition which otherwise is always discarded by the traditional Discrete Wavelet Transform (DWT). Unlike DWT, MODWT is not influenced by circular shifting of the input series whereas the values derived by the previous depend upon the starting point of the series (Percival and Walden, 2000). Likewise, MODWT wavelet coefficients modestly increase the effective degrees of freedom on each scale hence decreasing the variance of a certain wavelet-based statistics estimate (Safari, 2008).

Decomposing an infinite sequence $\left\{X_{t}\right\}$ of Gaussian random variables using the MODWT to $J_{0}$ levels theoretically involves the application of $J_{0}$ pairs of filters (Safari, 2008). The filtering operation at the $J$ th level consists of applying a wavelet (high pass) filter $\left\{\hat{h}_{j, l}\right\}$ to yield a set of wavelet coefficients following the Equation 1.

$\bar{W}_{j, l}=\sum_{l=0}^{L_{j-1}} \dot{h}_{j, l}^{*} X_{t-1}$

and a scaling (low-pass) filter $\left\{g_{j, l}^{*}\right\}$ to yield a set of scaling coefficients

$\bar{V}_{j, l}=\sum_{l=0}^{L_{j-1}} g_{j, l}^{\cdot} X_{t-1}$

for all times $t=\cdots \ldots \ldots ., 1,0,1, \ldots \ldots \ldots \ldots$ (Percival and Walden, 2000). Details of the theoretical basis for MODWT can be found in Cornish et al. (2006). For our specific application of MODWT, signals from satellite measurements that necessitate the retrieval of GHGs profiles are usually sampled at finite interval and discrete times i.e. satellite overpass time over the region. To complete the filtering operation at each level, then $\left\{X_{t}\right\}$ $t=0, \ldots \ldots . N-1$, MODWT treats the series as if it were periodic whereby the unobserved samples $X_{-1}, X_{-2}, \ldots \ldots \ldots X_{-N}$ are assigned the observed values $X_{N-1}, X_{N-2}, \ldots \ldots \ldots X_{0}$ (Safari, 2008). Thus, the MODWT coefficients are given by

$\bar{W}_{j, l}=\sum_{l=0}^{L_{j-1}} h_{j, l}^{*} X_{t-1 M O D N}$

and

$\bar{V}_{j, l}=\sum_{l=0}^{L_{j-1}} g_{j, l}^{\prime} X_{t-1 M O D N}$

for $t=0, \ldots \ldots . N-1$ as detailed in Cornish et al. (2006). Other than selecting appropriate boundary conditions, MODWT requires specification of the wavelet filter and the index $I_{0}$ for the maximum scale of interest (Safari, 2008). In the present case, the 'Haar' filter was utilized while the number of levels was set for the maximum of six (6) corresponding to the data size.

\section{Change Detections in Tropospheric Ozone Column}

Wavelet Toolbox in Mat lab provides functions necessary to analyze TOC measurements into progressively finer octave bands using decimated (down sampled) and non-decimated wavelet transforms, including the MODWT. MODWT multi resolution analysis enables the detection of patterns that are not visible in the raw data. For example, it is possible to measure the multi scale correlation between two signals or obtain multi scale variance estimates of signals to detect change points. In the current study, the later was utilized to determine the change points in TOC profiles over the entire East Africa. The following procedure was implemented in the quest of determining the change detections in the TOC time series data using the 'Haar' wavelet and the level of decomposition employed was maximum for the data size (6).

- $\quad$ Read the data from the excel files

- De-trend the data (removing the linear bias to bring the variations about the horizontal axis

Volume 2

Page 3 
- Obtain the maximal overlap discrete wavelet transform

- Check for the indices of changes in variance for each level of decomposition of the transform

- Use these indices to determine the monthly changes in TOC profiles over each study site

\section{RESULTS AND DiscusSions}

Global fluctuations in TOC are associated to anthropogenic influence (IPCC 2007). To quantify variabilities in TOC properties, we need robust techniques that can adequately handle TOC profiles multivariate characteristics in the environment. Among them is the MODWT that effectively quantifies the non-stationary characteristics of TOC properties as measured by a number of satellites over East Africa. The MODWT was used to determine the change points in TOC profiles via the 'Haar' wavelet. The main advantages of utilizing the MODWT is that its multiresolution and it can also automatically separates the trend from the time series data and further model and estimate the autocorrelated trend data as discussed in the following subsections.

\section{Change Detections in Total Ozone Column}

Ozone $\left(\mathrm{O}_{3}\right)$ was primarily measured on TOMS-Nimbus-7 (November 1978-May 1993), TOMS Meteor-3 (August 1991-December 1994), TOMS EP (July 1996-2005) and OMI (July 2004-To date) in that sequence. Where any of the two platforms perform measurements at the same time over a given site, the two measurements were averaged accordingly since the retrieval algorithm used was the same i.e. TOMS version 8 algorithm. Accumulatively all the measurements started in 1978 to 2015. A summary of TOC change points detected by MODWT over East Africa in each season are shown in Table 1 while the graphical representation of the same is in Figures 1-5.

Table 1. Estimated annual and seasonal change points in ozone over selected sites of East Africa from 1978 to 2015 using the MODWT

\begin{tabular}{|l|l|l|l|l|}
\hline \multicolumn{5}{|l|}{ Estimated change points in TOC } \\
\hline Interannual & \multicolumn{4}{|l|}{ Seasonal } \\
\cline { 2 - 5 } & DJF & MAM & JJA & SON \\
\hline NON & Feb 1983, Dec & Apr 1984, Apr 1985, & Jun 1984 & Sep 1993, Nov \\
& 2002, Jan 2008 & May 1993 & & 2000 \\
\hline
\end{tabular}

The various proxies associated with natural and anthropogenic processes that describe the chemical and dynamical changes in TOC over a given region as detailed by Chehade et al. (2014). These include Brewer Dobson Circulation (BDC), Quasi-biennial Oscillation (QBO), El Niño Southern Oscillation (ENSO), solar cycle and atmospheric aerosols. Utilizing the MODWT, it is notable that there are no interannual change points detected in TOC measurements over East Africa (Figure 1). Therefore, TOC measurements remain relatively constant interannually. As well, changes in TOC may also vary seasonally due to biomass burning and temporal evolution in precursor emissions i.e. $\mathrm{CO}_{2}, \mathrm{CH}_{4}$ and $\mathrm{NO}_{X}$ present in the atmosphere (UNEP 2006, Chehade et al., 2014).

During the December-January-February (DJF) season, MODWT successfully identified change points as detailed in Table 1 (also see Figure 2). Basically, during this season the entire East African region experiences dry spells with elevated temperature that may explain the observed changes in TOC profiles attributable to photochemical oxidation and limited removal process over the region (Shilenje and Ongoma, 2014). Additionally, increasing minimal temperature experienced particularly over urban sites in the region invoke the heat island effects that necessitate the transport of these pollutants from the surrounding regions therefore elevating TOC concentrations (Ongoma et al., 2013). On the contrary, dry spell with minimal temperature experienced over 
the sites of study (during June-July-August (JJA)) may explain the single change point observed over the region (see Table 1 and Figure 4). Low temperature experienced over the study sites in essence inhibits photochemical oxidation process which affects their variability hence no or limited change points noted during the study.

Estimated seasonal change points dominate the wet season during long rains i.e. March-April-May (MAM) over East Africa (see Table 1 and Figure 3). The significant number of change points (variability in TOC concentrations) revealed by the MODWT signifies the role of rainfall producing mechanism through thunderstorms and extreme rainfall and intrusion of stratospheric air (Mutai et al., 2015). Additionally, it has been established that biomass burning and lightening were the two main tropical sources of tropospheric $O_{3}$ and hence TOC variability over South Africa (Edward et al., 2003). It is also notable that during the September-October-November (SON) season, there is an enhanced variability in TOC concentrations i.e. higher number of change points as compared to JJA season (see Table 1 and Figure 5). This variability may be attributed to biomass and refuse burning, lightening and extreme rainfall and intrusion of stratospheric air over the region (Mutai et al., 2015).

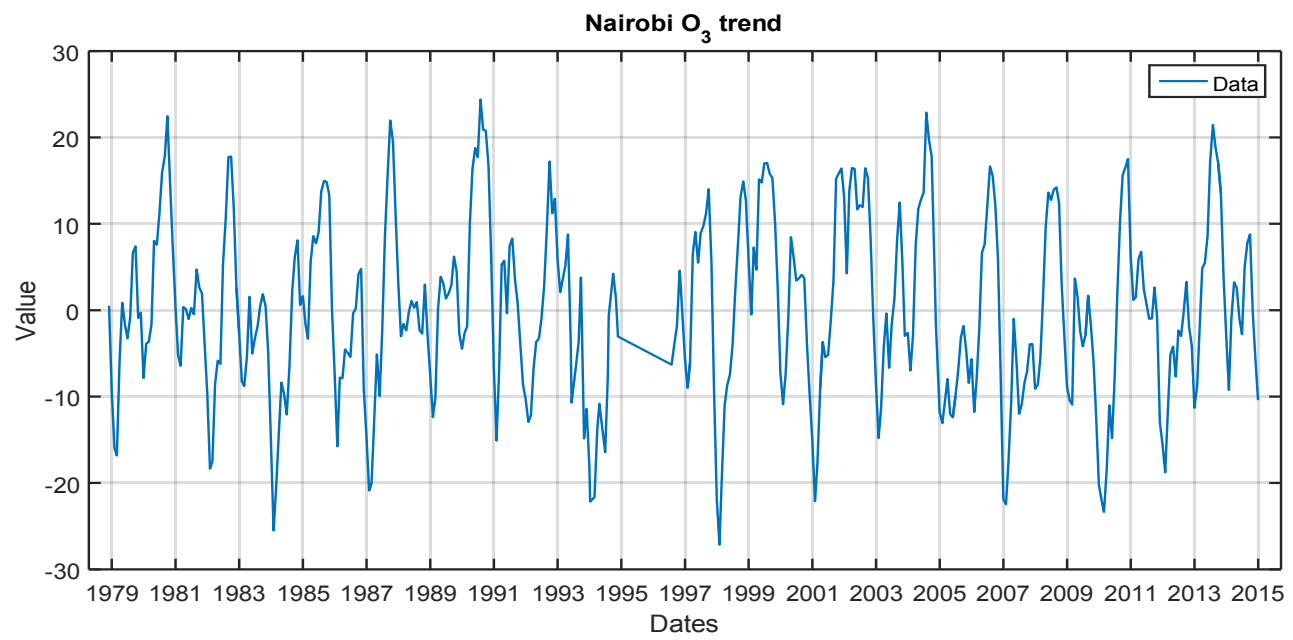

Figure 1. Estimated annual change points in Total Ozone Column measurements using MODWT

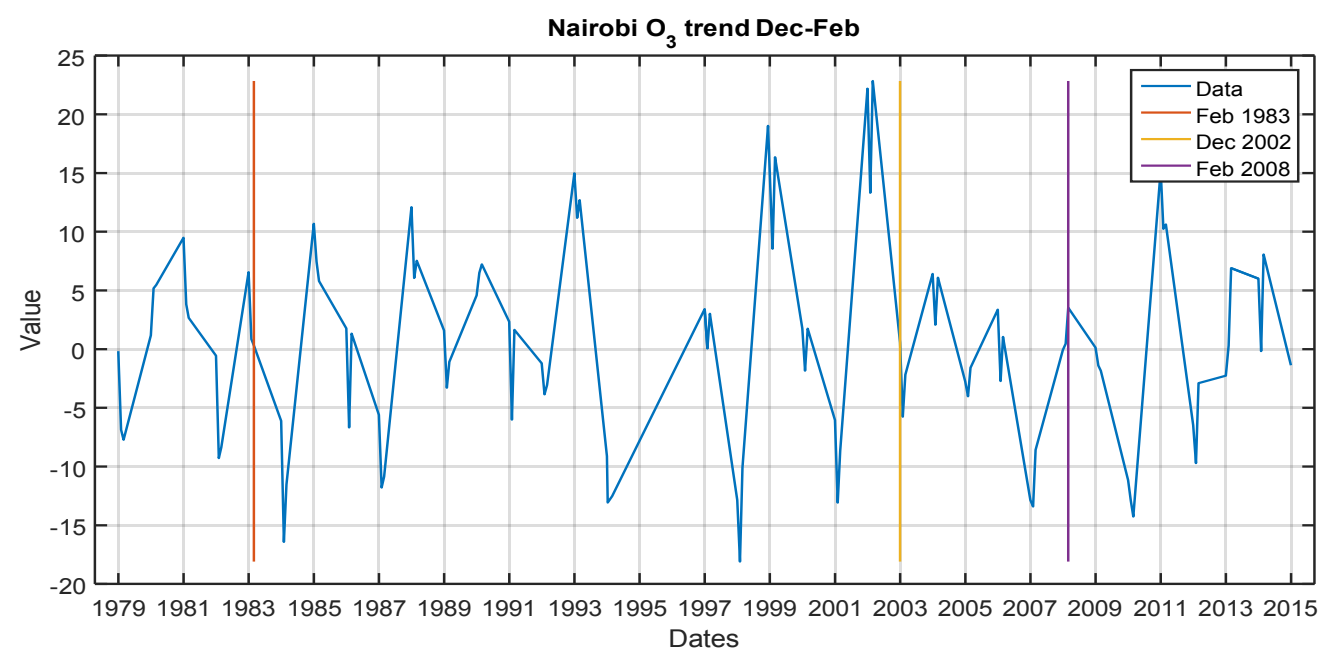

Figure 2. Estimated Seasonal change points in in Total Ozone Column using MODWT (DJF)

Volume 2 


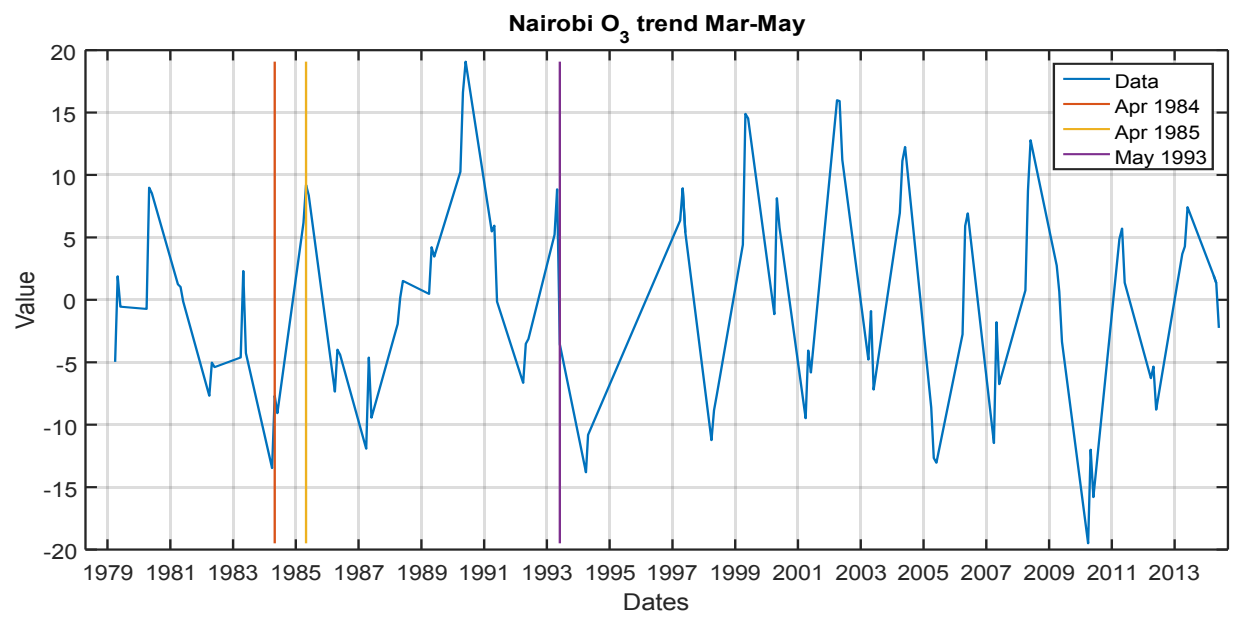

Figure 3. Estimated Seasonal change points in Total Ozone Column using MODWT (MAM)

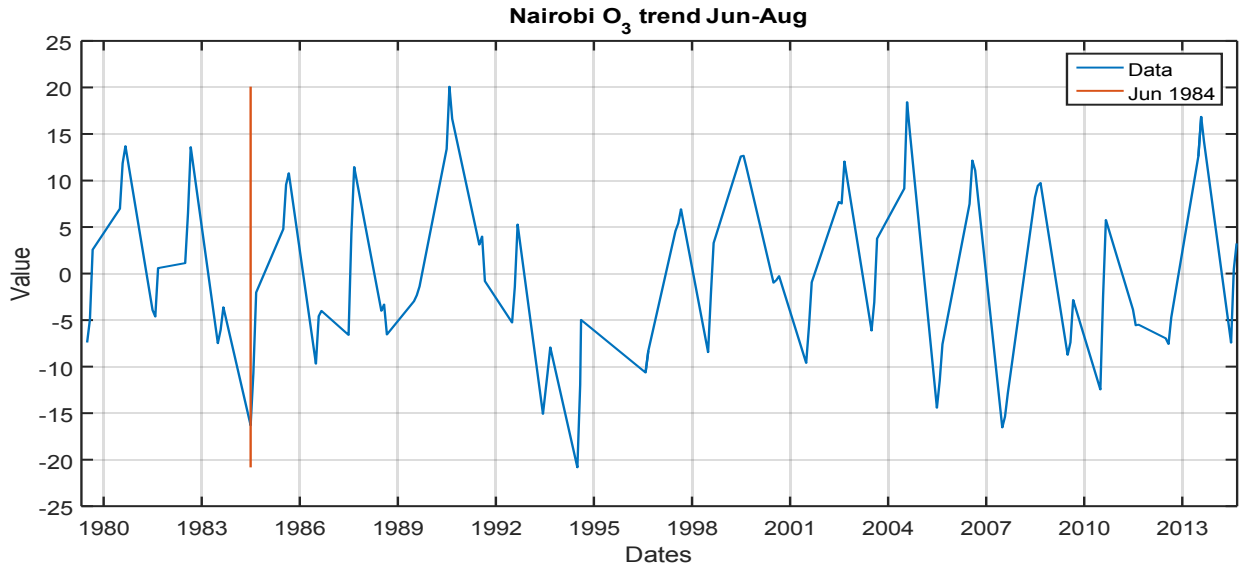

Figure 4. Estimated Seasonal change points in Total Ozone Column using MODWT (JJA)

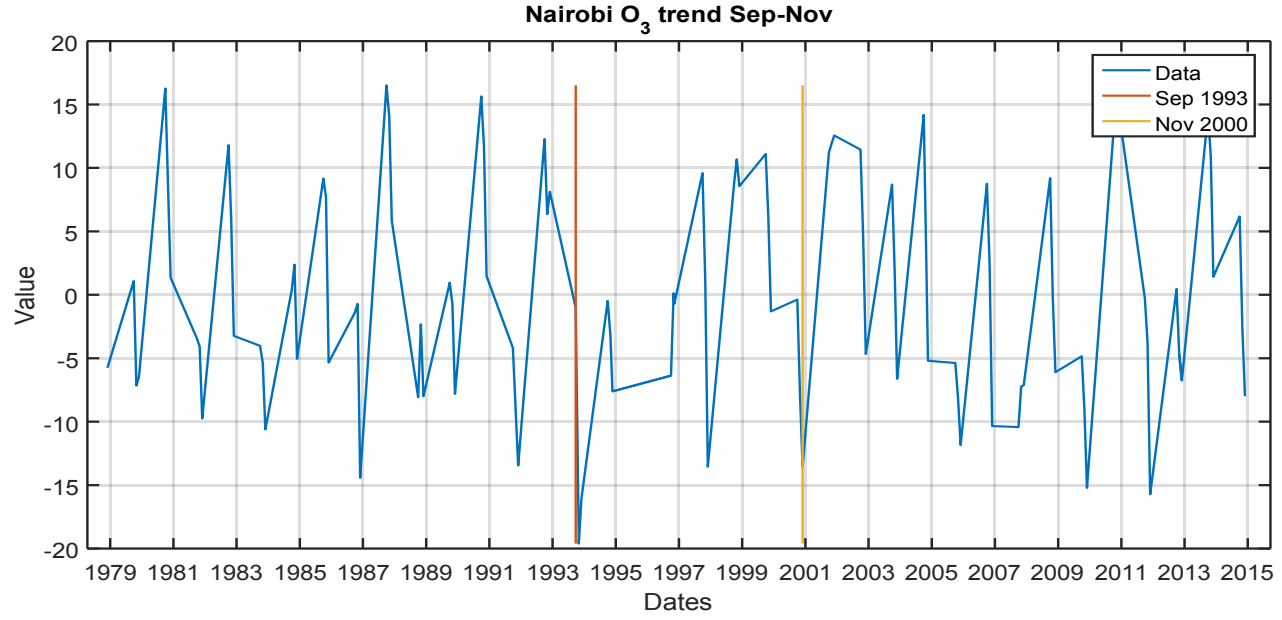

Figure 5. Estimated Seasonal change points in Total Ozone Column using MODWT (SON) 


\section{CONCLUSIONS}

Assessment of anthropogenic influence of TOC on climate change requires a comprehensive quantification of temporal characteristics. Quantification of TOC temporal variability with an aim of understanding its role on both regional and global climate change, we report on more than thirty years of TOC change point detection using MODWT. Interannual variability in TOC remained invariant during the study period while seasonal variability is evident and associated to anthropogenic influence, extreme rainfall, variability in precursor emissions of Ozone, stratospheric air intrusion and photochemical oxidation.

\section{ACKNOWLEDGEMENTS}

This work was supported by the National Council for Science and Technology Grant funded by the Government of Kenya (NCST/ST\&I/RCD/4TH call PhD/201). The authors wish to thank the Giovanni online data system that is developed and maintained by the NASA Goddard Earth Science Distributed Active Archive (NASA GES DISC) from which Total Ozone Column data from a number of satellites was obtained. I also acknowledge the support of the AFrican Spectral Imaging Network (AFSIN) through funding my travelling and subsistence to a conference on Multispectral imaging in Senegal.

\section{REFERENCES}

Beaulieu, C., Chien, J. and Sarmiento, J. L. (2012). Change point analysis as a tool to detect abrupt climate variations. Phil. Trans. R. Soc. A., 370:1228-1249.

Bolton, R. and Hand, D. (2002). Statistical Fraud Detection: A Review." Statistical Science, 17, 235-255.

Bortz, S.E. and Prather, M.J. (2006). Ozone, water vapor, and temperature in the upper tropical troposphere: Variations over a decade of MOZAIC Measurements. J. Geophys. Res., 111: 05305, doi:10.1029/2005JD006512.

Chehade, W., Weber, M. and Burrows, J.P. (2014). Total ozone trends and variability during 1979-2012 from merged data sets of various satellites. Atmospheric Chemistry and Physics, 14(13): 7059-7074.

Cornish, C.R., Bretherton, C.S. and Percival, D.B. (2006). Maximal overlap wavelet statistical analysis with application to atmospheric turbulence. Boundary-Layer Meteorology, 119(2):339-374.

Denman, K. L., Brasseur, G., Chidthaisong, A., Ciais, P., Cox, P. M., Dickinson, R. E., Hauglustaine, D., Heinze, C., Holland, E., Jacob, D., Lohmann, U., Ramachandran, S., da Silva Dias, P. L., Wofsy, S. C., Zhang, X. (2007). Couplings between changes in the climate system and biogeochemistry. Climate Change 2007: The Physical Science Basis. Contribution of Working Group I to the Fourth Assessment Report of the Intergovernmental Panel on Climate Change. Solomon, S., Qin, D., Manning, M., Chen, Z., Marquis, M., Averyt, K. B., Tignor, M., Miller, H. L. Cambridge, United Kingdom and New York, USA, Cambridge University Press.

Diab, R.D., Thompson, A. M., Mari, K., Ramsay, L and Coetzee, G. J. R. (2004). Tropospheric ozone climatology over Irene, South Africa, from 1990 to 1994 and 1998 to 2002. J. Geophys. Res., 109: D20301, DOI:10.1029/2004JD004793.

Edwards, D.P., Lamarque, J.F., Attié, J.L., Emmons, L.K., Richter, A., Cammas, J.P., and Burrows, J.P. (2003). Tropospheric ozone over the tropical Atlantic: A satellite perspective. Journal of Geophysical Research: Atmospheres (1984- 2012), 108(D8).

Erdman C and Emerson J.W (2007). bcp: An R package for performing a Bayesian analysis of Change point problems. Journal of Statistical Software, 23(3), 1-13. 
Forster, P. M. d. F. and Shine, K. P. (1997). Radiative forcing and temperature trends from stratospheric ozone changes. J. Geophys. Res. 102, 10841-10855.

IPCC, 2007: Climate Change 2007: The specific basis. Contribution of working group 1 for the fourth assessment report. Assesment Report of the Intergovernmental Panel on Climate Change [Solomon, S., Qin, D., Manning, M., Chen, Z., Marquis, M., Averyt, K.B., Tignor, M. and Miller, H. L. (eds)]. Cambridge University Press, Cambridge, United Kingdom and New York, NY, USA. 131-234.

IPCC, 2013: Climate Change 2013: The Physical Science Basis. Contribution of Working Group I to the Fifth Assessment Report of the Intergovernmental Panel on Climate Change [Stocker, T. F., D. Qin, G.-K. Plattner, M. Tignor, S. K. Allen, J. Boschung, A. Nauels,Y. Xia, V. Bex and P. M. Midgley (Eds.)]. Cambridge University Press, Cambridge, United Kingdom And New York, NY, USA, 1535. Doi: 10.1017/CBO9781107415324.

James, N. A. and Matteson, D. S. (2013). ecp: An R package for nonparametric multiple change point analysis of multivariate data. arXiv preprint arXiv:1309.3295.

Lähnemann, J. (2005). Validation of Satellite Ozone measurements over Nairobi using MAX-DOAS 2003-2004.

Mampaey M and Vreeken J (2011). Summarizing Categorical Data by Clustering Attributes. Data Mining and Knowledge Discovery, 24, 1-44.

Muggeo, V. M. and Adelfio, G. (2011). Efficient Change Point Detection for Genomic Sequences of Continuous Measurements." Bioinformatics, 27, 161-166.

Mutai, B. K., Muthama, J. N., Ng'ang'a, J. K. and Ngaina, J. N. (2015). Analysis of the temporal evolution of total column nitrogen dioxide and Ozone over Nairobi, Kenya using daily OMI measurements. EJSM., 8(5):530-540.

Ongoma, V., Muthama, N. J. and Gitau, W. (2013). Evaluation of urbanization influence on urban temperature of Nairobi City, Kenya. Global Meteorology., 2:doi:10-4081/gm.2013.el.

Percival, D. B. and A. T.Walden. (2000). Wavelet Methods for Time Series Analysis. Cambridge: Cambridge University Press.

Safari, D.W.I.A. (2008). Volatility and correlation: Modeling and forecasting using Support Vector Machines. PhD Thesis, Universität Karlsruhe.

Shilenje, Z.W. and Ongoma, V. (2014). Observed surface ozone trend in the year 2012 over Nairobi, Kenya. Atmósfera, 27(4):377-384.

Songa, C.M., Ndeda, J.H. and Ouma, G., (2015). Total Column Ozone Variability and Trends over Kenya using Combined Multiple Satellite-Based Instruments. Applied Physics Research, 7(5): p.87.

Székely, G.J and Rizzo, M.L (2005). Hierarchical Clustering Via Joint Between Within Distances: Extending Ward's Minimum Variance Method. Journal of Classification, 22(2), 151-183.

Székely, G.J and Rizzo, M.L (2010). Disco Analysis: A Nonparametric Extension of Analysis of Variance. The Annals of Applied Statistics, 4(2), 1034-1055.

Thompson, A.M., Balashov, N.V., Witte, J.C., Coetzee, J.G.R., Thouret, V. and Posny, F. (2014). Tropospheric ozone increases over the southern Africa region: bellwether for rapid growth in Southern Hemisphere pollution. .Atmospheric Chemistry and Physics, 14(18):9855-9869.

UNEP, (2006): Report on Atmosphere and Air Pollution. Africa Regional Implementation Review for the 14th Session of the Commission on Sustainable Development (CDS-14). United Nations Environmental Programme (UNEP), Nairobi.

Volume 2

Page 8 
Valks, P., Hao, N., Gimeno Garcia, S., Loyola, D., Dameris, M., Jöckel, P. and Delcloo, A., (2014). Tropical tropospheric ozone column retrieval for GOME-2. Atmospheric Measurement Techniques, 7(8): 2513-2530.

Zeileis A, Leisch F, Hornik K and Kleiber C (2002). \strucchange: An R Package for Testing for Structural Change in Linear Regression Models." Journal of Statistical Software, 7(2), 1-38. URL http://www.jstatsoft.org/v07/ i02.

Zhang, J., Tian, W., Xie, F., Tian, H., Luo, J., Zhang, J., Liu, W., and Dhomse, S. (2014). Climate warming and decreasing total column ozone over the Tibetan Plateau during winter and spring. Tellus B, 66. doi:http:// dx.doi.org/10.3402/tellusb.v66.23415.

Citation: J. W. Makokha , H. K. Angeyo, N.J. Muthama. "Long Term Change Point Detections in Total Ozone Column over East Africa via Maximal Overlap Discrete Wavelet Transform", American Research Journal of Physics, Volume 2; pp:1-9

Copyright (c) 2016 J. W. Makokha, H. K. Angeyo, N.J. Muthama. This is an open access article distributed under the Creative Commons Attribution License, which permits unrestricted use, distribution, and reproduction in any medium, provided the original work is properly cited. 